\title{
Sex differences in obesity rates in poor countries: Evidence from South Africa ${ }^{\text {is }}$
}

\author{
Anne Case ${ }^{\mathrm{a}, *}$, Alicia Menendez ${ }^{\mathrm{b}}$ \\ ${ }^{a}$ Research Program in Development Studies, Princeton University, United States \\ ${ }^{\mathrm{b}}$ Harris School of Public Policy, The University of Chicago, United States
}

\section{A R T I C L E I N F O}

\section{Article history:}

Received 3 July 2009

Received in revised form 8 July 2009

Accepted 9 July 2009

\section{Keywords:}

Sex differences

Obesity

Southern Africa

\begin{abstract}
A B S T R A C T
Globally, men and women face markedly different risks of obesity. In all but of handful of (primarily Western European) countries, obesity is much more prevalent among women than men. We examine several potential explanations for this phenomenon. We analyze differences between men and women in reports and effects of potential underlying causes of obesity-childhood and adult poverty, depression, and attitudes about obesity. We evaluate the evidence for each explanation using data collected in an urban African township in the Cape Town metropolitan area. Three factors explain the greater obesity rates we find among women. Women who were nutritionally deprived as children are significantly more likely to be obese as adults, while men who were deprived as children face no greater risk. In addition, women of higher adult socioeconomic status are significantly more likely to be obese, which is not true for men. These two factors childhood circumstances and adult SES - can fully explain the difference in obesity rates between men and women that we find in our sample. More speculatively, in South Africa, women's perceptions of an 'ideal' female body are larger than men's perceptions of the 'ideal' male body, and individuals with larger 'ideal' body images are significantly more likely to be obese.
\end{abstract}

(c) 2009 Elsevier B.V. All rights reserved.

\section{Introduction}

People living in developing countries are burdened not only by the infectious diseases of the developing world, but increasingly by the chronic diseases of the developed world. The incidence of obesity is on the rise in many poor countries (Popkin and Doak, 1998). Globally, men and women face different risks of obesity. Data from the World Health Organization (WHO) suggest that, in all but of handful of (primarily Western European) countries, obesity is more prevalent among women than men. In

\footnotetext{
This research has been supported by grants from the National Institute on Aging (R01 AG20275-01, P01 AG05842-14, and P30 AG024361).

* Corresponding author.

E-mail address: accase@princeton.edu (A. Case).
}

138 of 194 countries for which the WHO reports obesity statistics, women were more than $50 \%$ more likely to be obese (WHO Global InfoBase: Obesity and Overweight, available online at http://www.who.int/topics/obesity/ en/). The prevalence of obesity among women in Southern Africa is particularly high (Martorell et al., 2000). In South Africa, Puoane et al. (2002) find that $60 \%$ of African (Black) women in 1998 were either overweight or obese. Among Blacks in South Africa, the rate of obesity for women is five times higher than that for men. ${ }^{1}$

Chronic health risks associated with obesity include, inter alia, hypertension, coronary heart disease, stroke and

\footnotetext{
${ }^{1}$ We follow World Health Organization classifications that a person is overweight if his or her body mass index (BMI) - a measure of weight for height (kilograms per meter squared) - lies between 25 and 30, and is obese if his or her BMI is greater than 30 .
} 
diabetes. Recent work concludes that overweight Africans are not immune to these risks. Evidence from a South African demographic surveillance site finds that overweight and obese African women are at higher risk of hypertension (Case and Deaton, 2006), and that the two largest killers among residents aged 50 and above are stroke and congestive heart failure-both diseases associated with obesity (Kahn et al., 1999).

Recent literature points to several risk factors for obesity in developing countries. The focus of this work is generally on factors that shift the calorie intake-expenditure balance, including increased urbanization, which can lead to a reduction in physical activity; the availability of lower priced calories, which can lead to greater calorie consumption; and a "Westernization" of diets (Popkin, 1994; WHO, 2000; Prentice, 2006). Many cite the importation of high-fat foods into low income countries and movement away from traditional food stuffs as central underlying causes of the pandemic (FAO, 2006; Ulijaszek, 2003). All of these factors may contribute to the increased prevalence in obesity in the developing world. However, by themselves these factors cannot explain why the rates of obesity are significantly higher for women than for men in developing countries. ${ }^{2}$

There has been much recent work on the impact of the prenatal environment on predisposition to chronic illness and obesity in adulthood (Barker, 1998; Osmani and Sen, 2003; Whitaker and Dietz, 1998; McMillen et al., 2004; Armitage et al., 2008; Oken, 2009). ${ }^{3}$ But, by itself, this cannot explain why the rates of obesity are so dramatically different for women and men in adulthood.

In this paper, we examine several potential explanations for the much higher obesity rate observed for African women in South Africa. We analyze differences between men and women in reports and effects of underlying causes of obesity-specifically, childhood and adult poverty, depression, and attitudes about obesity. We evaluate the evidence for each explanation using data collected in 2004 and 2005 on the health, mental health and socioeconomic circumstances of individuals living in Khayelitsha, a densely populated shack township of over 500,000 people, on the outskirts of Cape Town, South Africa.

\section{Underlying causes of obesity}

Obesity results from an imbalance between calorie intake and expenditure. For policy purposes, it is important to understand both the proximate causes of obesity - the consumption of high-calorie foods, or lack of exercise, for example - and the underlying causes - that is, the reasons behind such behaviors. We focus on underlying reasons behind women's greater rates of obesity, including differences between sexes in the impact of childhood circumstance, adult SES, depression and opinions on ideal

\footnotetext{
2 A marked difference between the BMIs of Black men and women also developed in the United States in the second half of the 20th Century (Komlos et al., 2009).

${ }^{3}$ Ross and Beall, 2008 provide an overview to the recent literature on the consequences of interuterine growth retardation for adult health.
}

body shapes. We refer to these, collectively, as the underlying factors affecting the probability of obesity. (There are others which we are unable to address in the context of our data set.) We return to the relationship between the underlying and proximate causes in our discussion in Section 5.

\subsection{Childhood circumstance}

Early life conditions may have permanent sex-specific effects on appetite regulation, eating behaviors, and body weight gain patterns. Differential impacts of early life nutritional deprivation on males and females have been found across a range of experimental animal studies, although the physiological reasons for these differences are not well understood (Knight et al., 2007; Mcmillen and Robinson, 2005; Cupples, 2005; Lingas and Matthews, 2001). For example, male and female rats have been shown to respond differently to early postnatal exposure to hypothalamic neuropeptides known to affect the appetite regulation system (Varma et al., 2003; Wagner and Scholz, 2003).

In research conducted on early gestational undernutrition in laboratory rats, Anguita et al. (1993) find that malnutrition in the first 2 weeks of gestation is associated with lower than normal weight gain and fat deposition in male rats, but with greater than normal fat accumulation in female rats. They also speculate that this may be due to differences in the working of the hypothalamus between sexes. ${ }^{4}$

Evidence on sex-specific differences in the long-run impact of early-life deprivation in humans comes from research conducted on individuals who survived famine. Exposure to the Dutch famine of 1944-1945 during early gestation was associated with greater weight, higher BMI and greater waist circumference among 50-year-old women, but not among 50-year-old men (Ravelli et al., 1999). Related work finds that exposure to the Dutch famine while in utero led to increased weight and greater indexes of fat deposition at several tissue sites in women but not in men (Stein et al., 2007). Using a difference-indifference strategy, Luo et al. (2006) investigate the prevalence of adult obesity among men and women born in China during the Great Famine (1959-1962), comparing outcomes with adults who were too young to have been directly affected by the famine (born 1963-1966), and comparing outcomes between provinces where the famine was more and less severe. They find women who lived through the famine in provinces heavily hit face a significantly higher risk of obesity than do other women, while men's obesity patterns are not related to the famine.

Overall, this work on early malnutrition suggests that deprivation may alter regulatory mechanisms for energy intake and expenditure differentially by sex. In our data, we can examine whether and to what extent men and

\footnotetext{
${ }^{4}$ We thank Alan Rogol for confirming that there may be underlying hypothalamic response (leptin, melanocortin and its receptors) or differential levels of insulin resistance that are gender dependent. (Personal correspondence.)
} 
women raised in poor households, specifically those who report having gone hungry as children, face different risks of obesity, which would be consistent with a differential impact of early life nutritional deprivation on appetite and weight regulation in adulthood.

\subsection{Adult socioeconomic status}

An extensive literature has documented the extent to which resource allocation can vary by sex within households, in both developed and developing countries (Bergstrom, 1997). In many studies, women have been found to have a greater say in household decisions when their incomes constitute a higher fraction of total household income. When resources are scarce, women may choose not to eat, to guarantee that there is enough food for children. In addition, when resources are scarce, women may have less say in how money in the household is spent. Making decisions on who should eat, and having the power to make decisions on food spending, may result in differences in male-female obesity rates at different levels of household SES. In our data, we can examine whether and to what extent current household economic status is associated with differential obesity in men and women, and whether differences in obesity rates by SES can be explained by differences in women's contributions to the household resource base. ${ }^{5}$

\subsection{Depression}

On average, South African women report suffering from a greater number of symptoms of depression than do South African men (Case and Deaton, 2006). Studies in the US have generally found a positive association between obesity and depression in women, and either a negative association, or no association, between obesity and depression in men (Onyike et al., 2003). Depression may change eating patterns, and may lead to differential weight gain between men and women. In our data, we can examine both the extent to which men and women differ in their reports of depression, and the extent to which depression correlates differentially with obesity between men and women.

\subsection{Perceptions of body sizes}

Women and men's opinions on the relative attractiveness of different body shapes could potentially affect the sizes they wish to be. Across cultures, significant differences have been found in evaluations of body images. Holdsworth et al. (2004) show that among Senegalese women overweight figures are regarded as attractive and are associated with positive personal characteristics. Furnham and Baguma (1994) find significant differences in what is considered beautiful and healthy, in a comparison between Ugandan and British college students. Ugandans rate more obese bodies as more attractive

\footnotetext{
${ }^{5}$ Zagorsky (2005) examines the association between wealth and obesity in the US and finds a significant association between household wealth and obesity among Black women, but not among Black men.
}

and healthier than British students do, particularly in the case of female figures. In our data, we can examine the extent to which differences in obesity rates are associated with differences in male and female perceptions of what constitutes an 'ideal' male and female body.

\subsection{Determinants of obesity}

We assume the probability that an individual is obese $(y=1)$ is a function of vectors of childhood circumstances $\left(x_{c}\right)$, adult socioeconomic status $\left(x_{s}\right)$, adult attitudes, depression, and perceptions of the ideal body $\left(x_{d}\right)$. That is

$P(y=1)=x_{c} \beta_{c}+x_{s} \beta_{s}+x_{d} \beta_{d}+\varepsilon$.

The coefficients on childhood and adult circumstances provide reduced form estimates of the way these underlying characteristics affect obesity. We can also use them to characterize the reasons for women's much greater rates of obesity. Specifically, we quantify differences between men and women in their endowments of variables that determine obesity, and differences in the impact of these variables, by decomposing Eq. (1) using a Blinder-Oaxaca decomposition. ${ }^{6}$ Re-writing Eq. (1) for women $(F)$ and men $(M)$ as

$P^{k}(y=1)=\sum_{i} x_{i} \beta_{i}^{k}+e^{k} \quad$ for $k=F, M$,

the difference in obesity rates between women and men can be expressed as a gender effect, which measures the differences between sexes in the extent to which individual characteristics affect obesity; and a endowment effect, which measures differences in endowments of characteristics thought to influence obesity; and a residual, which picks up any remaining differences in rates between men and women. The gender effect can be written:

gender effect $=\sum_{i}\left(\beta_{i}^{F}-\beta_{i}^{M}\right) \overline{x_{i}}$

where $\overline{x_{i}}$ is the mean of characteristic $i$ over the sample. The endowment effect can be written:

endowment effect $=\sum_{i}\left(\overline{x_{i}^{F}}-\overline{x_{i}^{M}}\right) \overline{\beta_{i}}$

where $\overline{x_{i}^{k}}$ measures the mean of characteristic $i$ for sex $k$ in the sample, and $\overline{\beta_{i}}$ is the mean of the response to characteristic $i$ averaged between that estimated for women and that estimated for men. To the extent that one sex has more of a characteristic that affects obesity, this will contribute to the endowment effect. We estimate the gender and endowment effects for the underlying causes of obesity, and present them in Section 4.

\section{Data}

In 2004 and 2005, we collected data on 500 randomly selected households in Khayelitsha, an urban African township on the edge of Cape Town, with a population

\footnotetext{
${ }^{6}$ Costa-Font and Gil (2008) use a similar decomposition to examine gender height dimorphism in Spain.
} 
Table 1

Summary statistics by sex, Khayelitsha integrated family survey 20042005.

\begin{tabular}{|c|c|c|c|}
\hline & $\begin{array}{l}\text { Men } \\
(n=417)\end{array}$ & $\begin{array}{l}\text { Women } \\
(n=540)\end{array}$ & $\begin{array}{l}p \text {-Value of } \\
\text { difference }\end{array}$ \\
\hline Age & 35.58 & 36.41 & 0.345 \\
\hline \multicolumn{4}{|l|}{ Body mass index (BMI) } \\
\hline $\begin{array}{l}\text { Indicator: underweight } \\
\quad(\mathrm{BMI}<18.5)\end{array}$ & 0.060 & 0.011 & 0.000 \\
\hline $\begin{array}{l}\text { Indicator: normal } \\
\qquad(18.5 \leq \mathrm{BMI}<25)\end{array}$ & 0.647 & 0.219 & 0.000 \\
\hline $\begin{array}{l}\text { Indicator: overweight } \\
\qquad(25 \leq \mathrm{BMI}<30)\end{array}$ & 0.204 & 0.263 & 0.033 \\
\hline Indicator: obese (BMI $\geq 30$ ) & 0.089 & 0.507 & 0.000 \\
\hline \multicolumn{4}{|l|}{ Underlying causes of obesity } \\
\hline \multicolumn{4}{|l|}{ Childhood conditions } \\
\hline Indicator: went to school hungry & 0.379 & 0.367 & 0.703 \\
\hline Indicator: went to bed hungry & 0.377 & 0.338 & 0.220 \\
\hline $\begin{array}{l}\text { Indicator: ate at other } \\
\text { people's homes }\end{array}$ & 0.267 & 0.288 & 0.479 \\
\hline Child poverty index & 1.019 & 0.990 & 0.732 \\
\hline \multicolumn{4}{|l|}{ Adult socioeconomic status } \\
\hline Years of completed education & 6.28 & 6.76 & 0.016 \\
\hline Log (income per member) & 5.909 & 5.801 & 0.099 \\
\hline \multicolumn{4}{|l|}{ Depression index } \\
\hline 'Some' or 'Most of the time' & 1.966 & 2.783 & 0.000 \\
\hline \multicolumn{4}{|l|}{ Body shapes } \\
\hline Perceived current body shape & 3.306 & 4.123 & 0.000 \\
\hline Ideal body shape & 3.708 & 3.942 & 0.001 \\
\hline
\end{tabular}

in excess of 500,000 people. The township contains both houses with access to water and electricity, and shacks with access to neither. Most households have a family connection to the Eastern Cape, one of the poorest parts of South Africa (Leibbrandt et al., 2005), from which family members originally migrated. Poverty rates in the township are high, and the community faces major health problems in HIV and AIDS, TB, violence and malnutrition.

We surveyed every adult living in our sampled households individually, asking each about his or her family background, income and earnings, general health and mental health, and health related behaviors. All adults were weighed and measured. ${ }^{7}$

Table 1 presents summary statistics for 975 individuals, out of the 1001 adults in our 2004 and 2005 samples, for whom we have a BMI reading. ${ }^{8}$ Our focus is largely on the differences in obesity prevalence between the sexes, and for this reason we present the $p$-value of the statistical

\footnotetext{
7 These households were originally interviewed in 2002 and 2003. In the 2004 and 2005 follow-up, we succeeded in reinterviewing 427 original households, and 9 households where members had split from our original sample. These data are publically available on the University of Cape Town's DataFirst website at http://www.datafirst.uct.ac.za under the name Khayelitsha Integrated Family Survey 2002-2005.

8 Sex is missing for one observation. Of the remaining 25 missing values, height measurements were missing for 7 persons too ill to stand; 7 who did not want to be measured; and 6 persons for whom no reason for refusal was given. In addition, weight measurements were missing for one person too large for our scales (350 pounds), and 4 pregnant women.
}

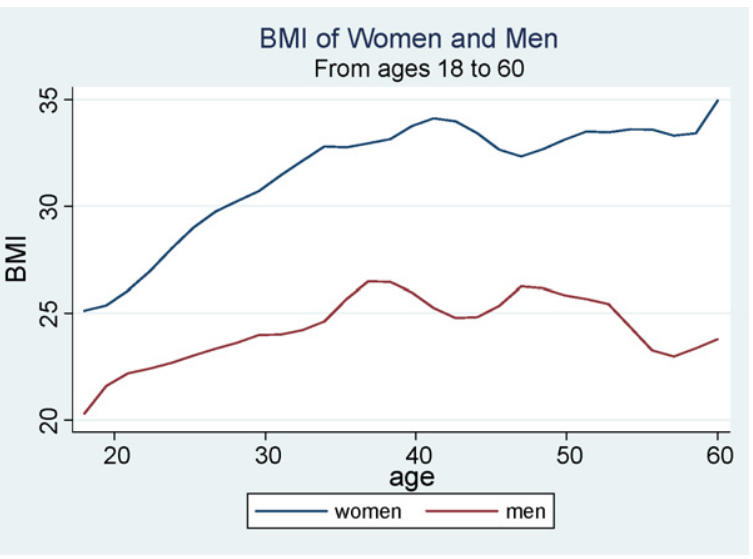

Fig. 1. Body mass indices for men and women, Khayelitsha Survey 20042005.

significance of the difference in sample means between men and women in column 3.

More than three-quarters of the women in our sample are either overweight or obese, true of only $30 \%$ of men surveyed. The patterns observed between and within sexes are similar to those found among urban Africans (Blacks) in the 1998 South African Demographic and Health Survey.

The BMI-age profiles underlying these statistics are presented in Fig. 1. Similar to the patterns found in other parts of South Africa, we find BMI increasing with age until age 40 . Thereafter, BMI is approximately constant with age. For women, stabilization in BMI occurs at a BMI well in excess of 30 . For men, it occurs at a BMI just shy of 25 , the WHO lower bound for 'overweight.'

From this cross-section, we cannot know whether these patterns represent age or cohort effects. The cross-section cannot tell us whether today's 20-year-old women, at age 35 , will continue to have average BMIs of 25 (as they do at age 20), or whether their BMIs will more closely resemble those of today's 35 year olds.

In addition, at every age, women's BMIs are 5-8 points higher than men's. Even the youngest women in our sample are overweight on average, registering BMIs in excess of 25 .

\subsection{Underlying causes: childhood circumstances}

We did not observe these adults as children, and so it is not possible to measure with any precision the nutritional risks they faced in early life. However, subjects had little difficulty telling us whether, as children, there were times when they went to school hungry, went to bed hungry, or ate at other people's homes because there was not enough food at home. More than a third of men and women report having gone to school and to bed hungry, and a quarter report having gone to other homes to eat. Differences

\footnotetext{
${ }^{9}$ In this paper, we present results on determinants of obesity (BMI greater than 30) for women and men. However, results are qualitatively unchanged if we analyze BMI in place of an indicator of obesity.
} 
between men and women in these reports are small, and are not statistically significant (Table 1 ).

In our analysis, we will use a 'childhood hunger index,' which we define as the sum of reports that a respondent went to school hungry, went to bed hungry, and ate at other people's houses because there was not enough food at home. Almost $60 \%$ of our sample report none of these events in childhood. Of the rest, approximately $10 \%$ report one of the three, $10 \%$ report two of the three, and $20 \%$ report all three. The overall means for men (1.02) and women (0.98) are very similar.

\subsection{Adult SES}

Both men and women have completed more than 6 years of schooling, with women reporting an extra half year, on average, relative to men. Educational attainment provides one of our measures of adult SES. An individual's current financial situation, measured using income per person, provides the other. A 'knowledgeable household member' (KHM) was asked about earnings, social transfers from the government (primarily pensions and grants), and private transfers coming into the household in a typical month, from which we generate a measure of income per person. On average, men reside in slightly wealthier households, measured using income per person.

\subsection{Depression}

We examine whether stress and depression play a role in obesity. We measure depression using an abbreviated version of the Center for Epidemiological Studies Depression (CES-D) index. ${ }^{10}$ We asked each person whether he or she had experienced any of 8 symptoms of depression in the last week and, if so, whether each occurred "most of the time," "some of the time," or "hardly ever." We asked about depression, sadness, crying, poor appetite, trouble sleeping, everything being an effort, feeling miserable, and not feeling able to 'get going.' From the answers received, we created a depression index, which is the sum of the number of times a person reported he or she had felt this symptom 'some of the time,' or 'most of the time.' Women report significantly more depressive symptoms than do men in our sample. On average, women report that they had experienced almost three of these symptoms 'some' or 'most of the time' in the past week, while men report two symptoms.

\subsection{Body images}

Every person interviewed was asked their perceptions about body images. Following an introduction that "Sometimes we have ideas about how we look, and how we might like to look," the respondents were shown pictures of eight people of their sex, whose images varied from being bone thin (rated as a 1) to being morbidly obese (rated as an 8).

\footnotetext{
${ }^{10}$ We originally piloted these questions with help from the University of Cape Town Medical School. For documentation on the reliability of using briefer forms of the CES-D, see Kohout et al. (1993).
}

These figures were originally used by Ziebland et al. (2002), who gave us permission to use them in our survey work (Fig. 2).

Each respondent was asked which best described their body size, and which best described the shape they would most like to have. Women on average perceive themselves to have a body size of ' 4.1 ,' and on average see a '3.9' as the 'ideal' body. Men see themselves as somewhat lighter, and on average would like to be a bit heavier than they are.

In summary, women and men report significant differences in years of completed schooling, depression symptoms, and ideas of an 'ideal' body shape. We turn in the next section to evaluate the extent to which these underlying causes can explain the differences in rates of obesity we find between men and women in South Africa.

\section{Determinants of obesity in South Africa}

Table 2 presents estimates of the underlying causes of obesity from OLS regressions, run separately for men and women, which control for age, age squared, an indicator for the survey year, and a constant term. Robust standard errors, which allow for correlation in the unobservables for individuals from the same households, are presented in parentheses. (Marginal effects from probit regressions are very similar. We focus on the OLS results because they allow a linear decomposition of sex differences into component parts.)

The first column presents results for women in which obesity is regressed on our childhood hunger index, and on the log of income per household member, as well as education, and our depression index. For women, childhood deprivation, measured using our childhood hunger index, is positively and significantly associated with obesity. Women who reported going to bed hungry, and to school hungry, and who ate at others' houses because there was not enough food, are 15 percentage points more likely to be obese than are women who report none of these. This result holds with or without controls for current socioeconomic status.

Higher socioeconomic status in adulthood, measured using years of education, is positively and significantly related to obesity in women. In addition, women in households with greater resources, measured using the log of income per member, are significantly more likely to be obese. Moving a woman from the 25th percentile to the 75th percentile of the distribution of income per person (measured at either the individual or the household level) is associated with an increase in obesity among women of 6 percentage points. ${ }^{11}$

Depression is not significantly associated with obesity in women. This continues to be true when the 8 component pieces of the index are entered separately, and when we divide responses into those reporting depression symptoms 'some' of the time, and those reporting them 'most' of

\footnotetext{
11 In results estimated but not reported in Table 2, we allowed the association between childhood deprivation and adult obesity to vary according to current socioeconomic circumstances. We found interaction terms between childhood hunger and log income per member to be small and insignificantly different from zero.
} 


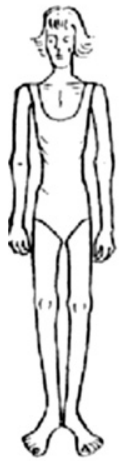

1

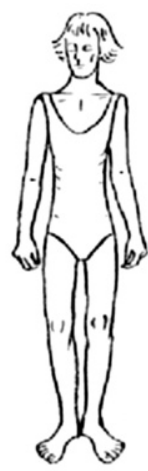

2

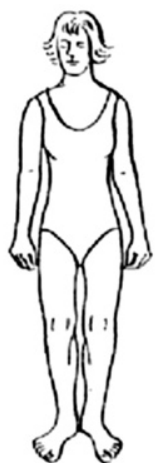

3

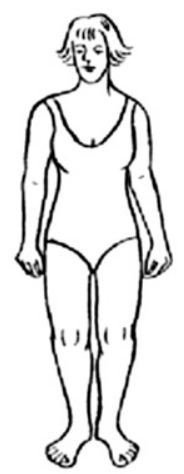

4

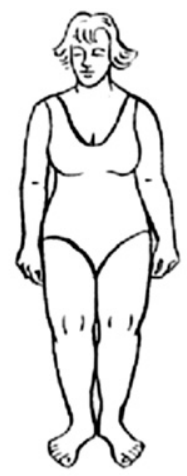

5

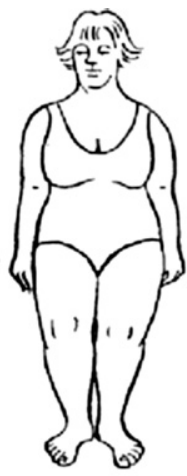

6

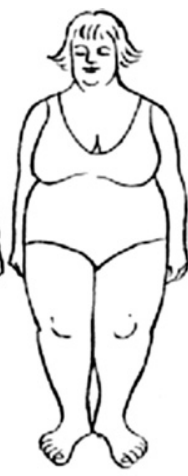

7

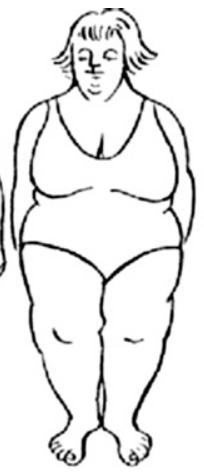

8

The illustrations of body shapes used for women

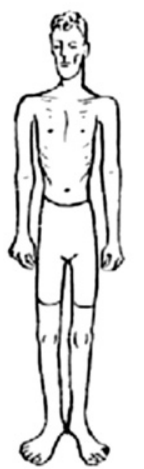

1

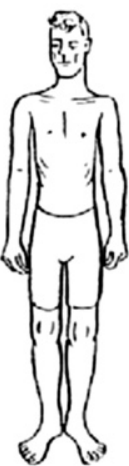

2

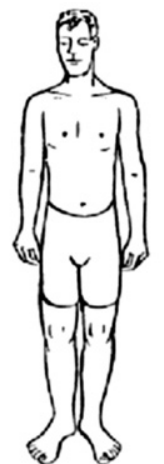

3

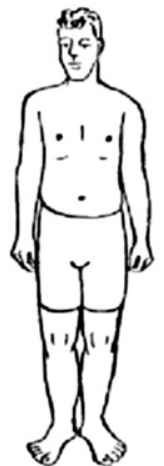

4

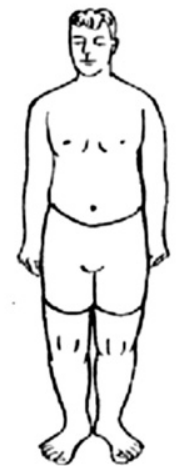

5

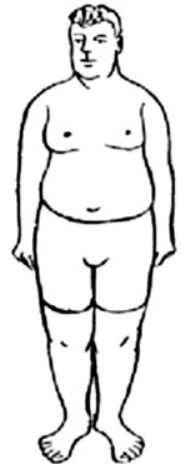

6

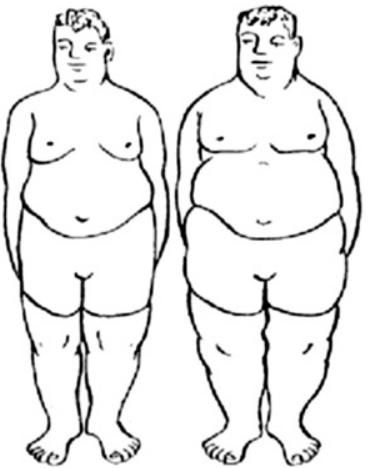

7
8

The illustrations of body shapes used for men

Fig. 2. Body images by sex (source: Ziebland et al., 2002).

the time. (These results were estimated, but are not reported in our tables).

The association between obesity and individual and household characteristics is altogether different for men. While men are equally likely to report having been raised

Table 2

Underlying determinants of obesity.

\begin{tabular}{lcr}
\hline & $\begin{array}{l}\text { Dependent variable }=1 \text { if BMI }>30,=0 \\
\text { otherwise }\end{array}$ \\
\cline { 2 - 3 } & Women $(1)$ & Men (2) \\
\hline Control variables & & \\
Childhood hunger index & $0.048^{* * *}(0.016)$ & $0.004(0.011)$ \\
Log (income/member) & $0.046^{* *}(0.021)$ & $-0.001(0.015)$ \\
Education & $0.020^{* * *}(0.009)$ & $0.008(0.005)$ \\
Depression index & $-0.006(0.008)$ & $-0.007(0.006)$ \\
$N$ observations & 517 & 389 \\
\hline
\end{tabular}

Notes: OLS regression coefficients reported, with standard errors in parentheses. Standard errors allow for correlation in the unobservables between individuals in the same household. Included in all regressions are controls for age, age squared, an indicator for the survey year, and a constant term.

"Significance at the $10 \%$ level.

** Significance at the $5 \%$ level.

*** Significance at the $1 \%$ level. in poor households, such reports by men are not associated with higher rates of obesity (column 2 ). In addition, current SES measured using log (income per member) has no significant association with obesity in men. Male obesity is also insignificantly related to reports of depression. We also find a small, insignificant association between education and obesity in men.

We decompose the obesity difference between women and men into gender and endowment effects in Table 3. The decomposition underscores the fact that differences in obesity are not due to differences in endowments of the economic variables examined here-the endowment effect is very close to zero $(-0.002)$. Obesity differences between the sexes appear, instead, to be due to the differences that socioeconomic status have on the probability of obesity. We find that childhood hunger accounts for $11 \%$ of the difference in obesity rates between women and men $(0.045 / 0.419)$. The impact of education accounts for $19 \%$ of the difference $(0.081 / 0.419)$. Sixty-five percent of the difference between men and women is due to the difference in the impact of current household income on obesity.

Differences in the impact of current and past economic circumstances explain $96 \%$ of the difference in obesity 
Table 3

Decomposition of the underlying determinants of obesity.

\begin{tabular}{|c|c|c|c|c|}
\hline \multicolumn{3}{|l|}{ Obesity rate, women } & & 0.507 \\
\hline \multicolumn{3}{|l|}{ Obesity rate, men } & & 0.089 \\
\hline \multicolumn{3}{|l|}{ Difference (women - men) } & & 0.419 \\
\hline \multicolumn{3}{|l|}{ Severity effect } & & 0.403 \\
\hline \multicolumn{3}{|l|}{ Prevalence effect } & & -0.002 \\
\hline \multicolumn{3}{|l|}{ Fraction explained } & & 0.957 \\
\hline \multirow{2}{*}{$\begin{array}{l}\text { Decomposition } \\
\text { by variable }\end{array}$} & \multicolumn{2}{|c|}{ Gender effect } & \multicolumn{2}{|c|}{ Endowment effect } \\
\hline & & $\begin{array}{l}\text { \% explained } \\
\text { by gender } \\
\text { effect }\end{array}$ & & $\begin{array}{l}\% \text { explained } \\
\text { by endowment }\end{array}$ \\
\hline \multirow{2}{*}{$\begin{array}{l}\text { Childhood hunger index } \\
\text { Log (income per member) }\end{array}$} & 0.045 & $10.7 \%$ & -0.001 & $-0.2 \%$ \\
\hline & 0.274 & $65.4 \%$ & -0.002 & $-0.5 \%$ \\
\hline Education & 0.081 & $19.3 \%$ & 0.007 & $1.7 \%$ \\
\hline Depression index & 0.002 & $0.5 \%$ & -0.006 & $-1.4 \%$ \\
\hline All & 0.403 & $96.2 \%$ & -0.002 & $-0.5 \%$ \\
\hline
\end{tabular}

Notes: The decomposition is based on OLS regression coefficients reported in Table 2.

rates by sex in our sample. We turn next to examine what these differences in the impact of SES may reflect.

\section{Understanding the effects of SES on obesity}

\subsection{Childhood deprivation}

Our childhood hunger index measures the extent to which respondents went hungry in childhood. We can distinguish whether its effects on women's obesity in adulthood appear to be due to nutritional deprivation, or to poverty more broadly, by examining several other measures of childhood deprivation that we collected on each respondent. We asked each whether his or her financial situation in childhood was "very comfortable, comfortable, just getting by, poor or very poor." Fifty percent of respondents answered that their households were "just getting by," and 37\% that they were "poor" or "very poor." In addition, we asked respondents whether their fathers had stable employment (a "regular pay job") when they were children (true for approximately twothirds of respondents).
Table 4 presents results of our childhood hunger index regressed against indicators of financial status in childhood and of whether the respondent's father had a regular pay job. Our hunger index is highly correlated with these measures of childhood economic status, as can be seen in the first two columns of the table. For both men and women, father not having had a regular pay job is associated with an increase of approximately 0.2 points in our childhood hunger index. The associations between the childhood hunger index and reports on childhood financial status are very similar between men and women. Adults who report that their families' financial situations were either "very comfortable" or "comfortable" have a hunger index that is, on average, 2.2 points lower than those who report that their families were "very poor," the reference group for this regression. Those whose families were "just getting by" report a hunger index that is 1.8 points lower, and those whose families were "poor" report a hunger index that is $0.4-0.6$ points lower than those whose families were "very poor." The difference between reporting that their families were "comfortable" and reporting that they were "just getting by" is significant, as is the difference between reporting "just getting by" and being "poor." Jointly, the reports of childhood financial wellbeing are highly significant for both women ( $F$ test $=92.92, p$-value $=0.000)$ and men $(F$-test $=66.59, p$ value $=0.000$ ).

We test whether it is nutritional deprivation, or economic deprivation in childhood more broadly, that is associated with obesity in adult women, by adding all three measures of childhood SES to our obesity equations. Results from these OLS regressions are presented in the last two columns of Table 4 . We find that the inclusion of indicators of family financial status in childhood, and of whether the respondents' fathers held regular pay jobs, are not significantly associated with obesity for either women or men. The only measure of childhood circumstance that is significantly associated with obesity in adulthood is our indicator of hunger in childhood for women. We find that each unit increase in our childhood hunger index is associated with a 7 percentage point increase in the probability that a woman is obese.

Table 4

Childhood SES and adult obesity.

\begin{tabular}{|c|c|c|c|c|}
\hline & \multicolumn{2}{|c|}{ Dependent variable: childhood hunger index } & \multicolumn{2}{|c|}{ Dependent variable: obesity in adulthood } \\
\hline & Women & Men & Women & Men \\
\hline Childhood hunger index & - & - & $0.068^{* * *}(0.023)$ & $-0.005(0.015)$ \\
\hline $\begin{array}{l}\text { Childhood family finances were } \\
\text { "Very comfortable" or "comfortable" } \\
\text { "Just getting by" } \\
\text { "Poor" }\end{array}$ & $\begin{array}{l}-2.155^{* * *}(0.172) \\
-1.766^{* * *}(0.177) \\
-0.363^{*}(0.194)\end{array}$ & $\begin{array}{l}-2.257^{* * *}(0.189) \\
-1.782^{* * *}(0.195) \\
-0.547^{* *}(0.220)\end{array}$ & $\begin{array}{r}0.126(0.113) \\
0.019(0.094) \\
-0.020(0.086)\end{array}$ & $\begin{array}{r}-0.049(0.069) \\
0.011(0.061) \\
-0.014(0.057)\end{array}$ \\
\hline $\begin{array}{l}\text { Father did not have a "regular pay job" } \\
\text { F-Test: joint significance of family finance } \\
\text { indicator variables }\end{array}$ & $\begin{array}{l}0.160(0.120) \\
92.92\end{array}$ & $\begin{array}{l}0.235^{*}(0.128) \\
66.59\end{array}$ & $\begin{array}{l}0.008(0.051) \\
1.02\end{array}$ & $\begin{array}{l}0.022(0.035) \\
0.79\end{array}$ \\
\hline Number of observations & 468 & 367 & 468 & 367 \\
\hline
\end{tabular}

Notes: Also included are age, age squared, an indicator for survey year, and a constant term. All regressions allow for correlation in the unobservables for observations from the same household.

* Significance at the $10 \%$ level.

** Significance at the $5 \%$ level.

*** Significance at the $1 \%$ level. 
Table 5

Own-income, household income and obesity.

\begin{tabular}{|c|c|c|c|c|}
\hline & \multicolumn{4}{|c|}{ Dependent variable: obesity in adulthood } \\
\hline & \multicolumn{2}{|l|}{ Women } & \multicolumn{2}{|l|}{ Men } \\
\hline & $(1)$ & $(2)$ & $(3)$ & $(4)$ \\
\hline Total household income per month (R1000) & $0.032^{* *}(0.015)$ & $0.021(0.019)$ & $0.008(0.009)$ & $0.000(0.010)$ \\
\hline Own earnings from work per month (R1000) & - & $0.054^{*}(0.029)$ & - & $0.019(0.021)$ \\
\hline Monthly child support grant receipt (R1000) & - & $0.494^{* * *}(0.174)$ & - & - \\
\hline Childhood hunger index & $0.041^{* *}(0.016)$ & $0.036^{* *}(0.016)$ & $0.010(0.011)$ & $0.009(0.011)$ \\
\hline Number of observations & 504 & 503 & 364 & 364 \\
\hline
\end{tabular}

Notes: OLS regression coefficients are reported, with standard errors that allow for correlation in the unobservables for observations from the same household. Included in all regressions are controls for age, age squared survey year, number of household members, and a constant term. The sample excludes 5 outliers for whose reported total household monthly income exceeded R10,000.

Significance at the $10 \%$ level.

Significance at the $5 \%$ level.

**** Significance at the $1 \%$ level.

Future work is warranted to see what aspects of childhood nutritional deprivation are responsible for adult obesity in women. Such work must combine biology and social science, if we are to understand why this effect in childhood affects only women. Such work may contribute to our understanding of the seemingly ironic finding that poor countries struggling with malnutrition must also cope with obesity (Khan, 2006).

\subsection{Adult SES}

We find that, for women, obesity is associated with higher adult SES. The same is not true for men. In this section, we examine potential explanations for this difference. We present our findings in two parts. We find that women's own incomes fully explain the association between total household income and women's obesity. Part of the association between women's incomes and their obesity appears to work through the fact that women with higher incomes have a greater say in household decisions on food spending. After presenting these results, we examine why women's control over resources leads them to be obese, while we find no parallel effect for men. Given that women and men have different perceptions of 'ideal' body shapes, we examine whether they use the resources under their command to move toward different ideals.

\subsection{Women's incomes and obesity}

We examine the relationship between own-income and obesity in Table 5, where we regress the probability of being obese on different components of household income. In order to analyze different parts of household income, we present results for income in levels, rather than in logs, so that we do not lose observations for respondents who report no income.

Consistent with the results presented in Table 2, we find that women residing in households with greater total household income are significantly more likely to be obese. In contrast, we find no association between household income and men's risk of obesity (column 3 ).

Decomposing total household income into component parts makes it clear that the association between house- hold income and a woman's obesity is driven by women's own income (column 2). Women in our survey report two large sources of income: their own earnings, and their receipt of child support grants. Fully a third of all women report earnings from work, and a third report receipt of a child support grant from the government. ${ }^{12}$ Adding women's incomes from these sources to our obesity regressions, we find both women's earnings and their child grant receipt are positively and significantly correlated with obesity, while the estimated effect of total household income becomes smaller and insignificantly different from zero. ${ }^{13}$ On average, each additional R1000 per month in own-earnings is associated with a 5.4 percentage point increase in obesity for women, holding all else constant. Women receiving R170 in the form of a government child support grant are 8.4 percentage points more likely to be obese than are women not receiving a grant $(0.494 \times 0.170)$. For men we find no effect of either total household income, or own-earnings, on obesity (column 4).

We turn to investigate why we might find it is women's own income, rather than household income, that is significantly associated with obesity. It is possible that obesity and women's own incomes are driven by particular third factors-such as illness, marital status, or fertility history. Alternatively, it is possible that a woman's income changes her status as a decision-maker in the household. In

\footnotetext{
${ }^{12}$ In contrast, only $5 \%$ of women report receipt of an old age pension (most are not age eligible). Another 5\% report a disability grant. With respect to child support grants, at the time of our survey, children from ages 0 to 7 were eligible to receive between R160 to R180 per month through a primary care giver, who is generally (but not restricted to be) the child's mother, if the primary care giver's monthly income was less than R1100 and he or she was living in an informal house or shack. Men are only rarely reported to be child grant recipients. In our data, 3 men were so named.

13 To interpret coefficients in column 2, note that women's own income is one component in total household income, so that the coefficient on women's own income answers the question "holding constant total household income, how does the probability of obesity change when a Rand comes into the household through this woman, instead of through a different household member?" Given the linearity of the model, a specification that used 'woman's own income' and 'all other household income' would only result in a mechanical rearrangement of the
} 
Table 6

Alternative explanations for the impact of women's own income.

\begin{tabular}{|c|c|c|c|c|}
\hline & \multicolumn{4}{|c|}{ Dependent variable: obesity in adulthood } \\
\hline & \multicolumn{4}{|c|}{ Women with additional controls for } \\
\hline & Baseline & Health & Marriage & Fertility \\
\hline Total household income per month (R1000) & $0.021(0.018)$ & $0.021(0.018)$ & $0.012(0.018)$ & $0.021(0.018)$ \\
\hline Own earnings from work per month (R1000) & $0.054^{*}(0.029)$ & $0.052^{*}(0.029)$ & $0.069^{* *}(0.029)$ & $0.056^{*}(0.029)$ \\
\hline Monthly child support grant receipt (R1000) & $0.494^{* * * *}(0.174)$ & $0.489^{* * * *}(0.173)$ & $0.417^{* *}(0.175)$ & $0.389^{* * *}(0.197)$ \\
\hline Childhood hunger index & $0.036^{* *}(0.016)$ & $0.038^{* *}(0.017)$ & $0.034^{* *}(0.016)$ & $0.032^{*}(0.017)$ \\
\hline Indicator: poor health at present & - $\quad-120$ & $-0.043(0.054)$ & - $\quad-12$ & - $\quad-120$ \\
\hline Indicator: reports feeling weak & - & $0.074(0.081)$ & - & - \\
\hline Indicator: reports body-ache & - & $-0.000(0.052)$ & _ & _- \\
\hline$F$-Test: health variables ( $p$-value) & - & $0.72(0.539)$ & - $\quad$ - & - \\
\hline Indicator: married or living with partner & - & - & $0.118^{* *}(0.050)$ & - \\
\hline Number of living children & - & - & - $\quad-12$ - & $0.027(0.019)$ \\
\hline Number of observations & 503 & 502 & 503 & 499 \\
\hline
\end{tabular}

Notes: OLS regression coefficients are reported, with standard errors that allow for correlation in the unobservables for observations from the same household. Included in all regressions are controls for age, age squared, survey year, number of household members, and a constant term. The sample excludes 5 outliers for whose reported total household monthly income exceeded R10,000.

* Significance at the $10 \%$ level.

** Significance at the $5 \%$ level.

*** Significance at the $1 \%$ level.

Table 6, we present results of regressions in which we examine these possible explanations.

\subsubsection{Women's health status}

Illness is a possible third factor that may influence both women's income and obesity. Perhaps women who are healthy are larger, and earn money, while women who are ill waste away, unable to work. We control for women's health status in column 2 of Table 6 , where we re-run the results presented in Table 5 for women, but here with additional indicator variables for whether a woman reports herself in 'fair' or 'poor' health; or reports feeling 'weak'; or reports body-ache. We do not find that these health indicators are significantly correlated with obesity. Neither do they reduce the effect of own-income on the probability of being obese.

We have also investigated whether obese and nonobese women report differences in the difficulties they face in carrying out activities of daily living (dressing, bathing, eating, toileting, taking a bus or taxi, lifting heavy objects (5 kg), or walking 200-300 m). In regressions run but not reported, we analyzed whether obesity was significantly associated with an indicator of reporting having difficulty with at least one of these activities. We found no significant difference in the probability that obese and non-obese women reported difficulties with at least one of these daily activities. Inclusion of an indicator of reporting difficulty with any of the activities of daily living does not change the patterns we observe between obesity on one hand, and own-earnings and child grants on the other.

\footnotetext{
${ }^{14}$ We find this explanation unlikely, given the results of more recent survey work we have been conducting in Khayelitsha as part of the Cape Area Panel Study (CAPS). In the fourth wave of the CAPS survey, both men and women were asked about women's ideal body sizes. We found men and women are in close agreement on the 'ideal' size for women. Results available upon request.
}

\subsubsection{Marital status}

If men prefer women who are not obese, we would expect that an obese woman would be more likely to live in a household without a partner, which would increase the probability that her income was a larger share of total household income. This, then, would induce the correlation between own-income and obesity observed in the data. ${ }^{14}$ We test this explanation by controlling for marital status in column 3 of Table 6. Specifically, we include an indicator that a woman reports living with a spouse or partner. We find women who are co-habitating are significantly more likely to be obese, and that the inclusion of the marital status indicator has little effect on the coefficients of own-income.

\subsubsection{Children}

Women's obesity, and their earnings from work and child support, may both be correlated with the fact that she has given birth. In column 4 , we include a variable for the number of living children each woman reports. We find it is insignificantly associated with obesity, and has little effect on own-income coefficients. (Alternative specifications, such as those that include an indicator for having any children, yield similar results.)

\subsubsection{Household decision-making}

Women may be significantly more likely to control household food spending when their own incomes are higher. In the household module of our Khayelitsha survey, we asked the knowledgeable household member which members of the household "had the most say in decisions about spending on food." Table 7 presents regression results for being identified as such a decision-maker, for women living in households that contain both adult men and women as members. We present regression results for having 'the most say' on food spending regressed on total household income, earnings from work and child grant receipt. In this regression, we control for the member's 
Table 7

Decision-making on food spending and women's obesity.

\begin{tabular}{|c|c|c|c|}
\hline & \multicolumn{3}{|l|}{ Women dependent variable } \\
\hline & $\begin{array}{l}=1 \text { if this adult is reported to } \\
\text { have the "most say" on food } \\
\text { spending }\end{array}$ & Obesity & Obesity \\
\hline Indicator: respondent has 'most say' on food spending & - & $0.151^{* *}(0.070)$ & $0.111^{*}(0.062)$ \\
\hline Total household income per month (R1000) & $-0.007^{*}(0.004)$ & $-0.001(0.007)$ & $0.004(0.008)$ \\
\hline Own earnings from work per month (R1000) & $0.048^{* *}(0.022)$ & $0.005(0.028)$ & $0.008(0.029)$ \\
\hline Monthly child support grant receipt (R1000) & $0.654^{* * *}(0.138)$ & $0.440^{* *}(0.188)$ & $0.413^{* *}(0.173)$ \\
\hline Number of observations & 398 & 398 & 513 \\
\hline
\end{tabular}

Notes: OLS regression coefficients are reported, with standard errors that allow for correlation in the unobservables for observations from the same household. Included in all regressions are controls for age, age squared, survey year, and a constant term. The sample in columns 1 and 2 is restricted to women who live in a household with at least one adult male.

* Significance at the $10 \%$ level.

** Significance at the 5\% level.

*** Significance at the $1 \%$ level.

education, age, and age squared, which may affect a member's decision-making powers within the household.

We find that women's incomes make them significantly more likely to be reported as the decision-maker for household food spending. Controlling for women's own incomes, the effect of total household income is small and insignificantly different from zero. A woman's own income appears to increase her voice in household food spending decisions.

In turn, being the decision-maker for household food spending is significantly associated with obesity in women. On average, women who have the most say in household food spending are 10-15 percentage points more likely to be obese (columns 2 and 3 of Table 7). Inclusion of an indicator that the respondent has been identified as having the most say on food spending reduces the estimated effects of own-earnings and child grant receipt on women's obesity substantially. As was true of our earlier results, we find no effects of total household income, or own-earnings, or having the most say on food spending, on men's obesity (results estimated, but not reported in Table 7 ).

\subsubsection{Proximate causes of obesity}

Most of the effect of women's incomes on obesity works through latent calorie intake and expenditure variables. There is no significant association between women's own earnings and reported meal sizes, or reported exercise or sports. Women who receive child support grants report significantly higher sugar intake. Those who report higher earnings are more likely to report that they drink soda. Taken overall, there must be many unobserved energy variables that vary with women's incomes.

While it could be the case that women are more likely to be obese because they are less likely than men to work in jobs that require manual labor, this is not the explanation for our findings. Forty-six percent of working men report blue collar work-true of $51 \%$ of working women. Obesity rates by type of work are reported for men and women in Table 8. Both men and women, those who work are significantly more likely to be obese than non-working counterparts, and we find no significant difference in obesity rates between men in white and blue collar jobs, or between women in white and blue collar jobs.

\subsubsection{Perceptions of body type}

Why are women with higher incomes more likely to be obese? One possibility is that women admire larger body sizes. When we ask women about their body size, we find that women with larger BMIs are significantly more likely to report that they are larger, measured using the body size pictures. On average, each one-unit increase in BMI is associated with women stating that their own body size is 0.12 pictures larger. Fig. 3 presents evidence that, on average in our survey, a woman's perceived body size equals her ideal body size at a BMI just below 30-which is the WHO lower bound for obesity. Women with BMIs below thirty, on average, report that their 'ideal' is larger than their actual body size, while women with BMIs above thirty believe their ideal is below their actual size. On average, women's ideal size is equal to her self-perceived body size at a BMI of 29.45. In contrast, for men, ideal size is equal to selfperceived body size at a BMI of 24.23. If women are targeting a BMI of 30 , while men are targeting a BMI of 25 , this could lead to women with money using it, in part, to move their BMIs toward 30.

Table 8

Obesity rates by type of employment.

\begin{tabular}{lcc}
\hline & Men & Women \\
\hline Obesity rate: not working & $0.036(0.014)$ & $0.430(0.029)$ \\
Obesity rate: blue collar & $0.097(0.026)$ & $0.631(0.044)$ \\
$\begin{array}{l}\text { Obesity rate: white collar } \\
\text { F-Test: not working = blue }\end{array}$ & $0.159(0.034)$ & $0.600(0.045)$ \\
$\quad \begin{array}{l}\text { collar }(p \text {-value) } \\
\text { F-Test: not working = white } \\
\quad \text { collar }(p \text {-value) }\end{array}$ & $11.90(0.001)$ & $10.54(0.000)$ \\
$\begin{array}{l}\text { F-Test: blue collar = white } \\
\text { collar }(p \text {-value) }\end{array}$ & $2.16(0.143)$ & $0.24(0.622)$ \\
Observations & 416 & 540 \\
\hline
\end{tabular}

Notes: Means presented, with standard errors in parentheses. Standard errors allow for correlation between unobservables for readings from the same household. 


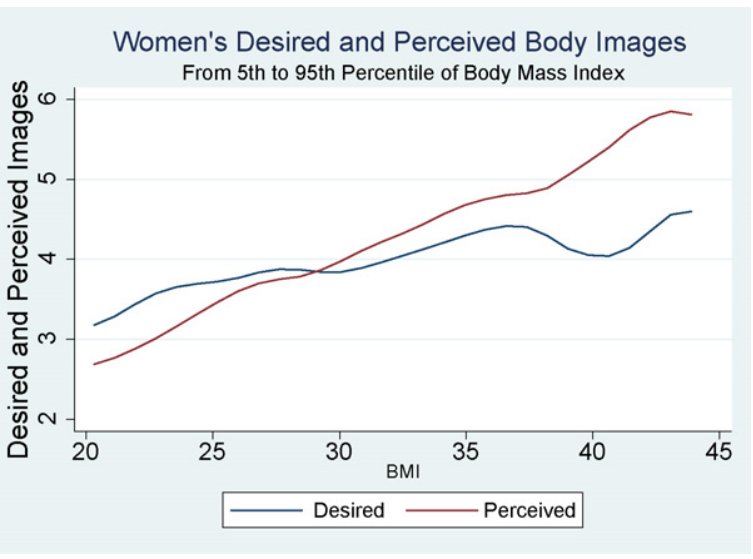

Fig. 3. Perceived body shapes and desired body shapes for women.

\section{Conclusions}

Using data from an African township in South Africa, we are able to identify underlying causes of differences between men's and women's obesity. We find that poverty in childhood, and greater access to resources in adulthood, lead women to be at significantly greater risk of obesity than are men. In adulthood, there is a significant and substantial difference in the body sizes to which men and women aspire. Women with more control over their resources appear to use these resources to reach and maintain larger body sizes.

Understanding the differences that men and women face in their risks of obesity is a necessary and important first step for effective policy intervention. If women aspire to large body sizes, then we would not expect a campaign that spread general information on the calorie, fat and nutrition content of food would take us very far in reducing the obesity risk that women face. One way to address women's high prevalence rates may be to better educate women on the relevant risks that they face when their BMI becomes large. In that way, women's perceptions of an ideal body size may change.

There may be an upper bound on the extent to which such campaigns will be successful, however, if a woman's ability to regulate her appetite is compromised by the nutritional deprivation she endured in utero and in early life. Our results on the differences in obesity risk faced by men and women, who reported similar childhood nutritional deprivation, suggest that the biology of obesity risk cannot be fully understood without understanding early-life economic disadvantage, and that the impact of socioeconomic status on obesity cannot be understood without a biological framework that can explain why women and men, facing the same nutritional deprivation as children, face quite different biological risks as adults.

\section{Acknowledgements}

We are grateful to Dr. Ingrid le Roux and the Philani Nutrition Programme for their generous help. We thank
Alice Muehlhof for expert help with the data, Karla Hoff and seminar participants for many useful comments, and especially John Komlos, who provided many helpful suggestions.

\section{References}

Anguita, R.M., Sigulem, D.M., Sawaya, A.L., 1993. Intrauterine food restriction is associated with obesity in young rats. Journal of Nutrition 123 , 1421-1428.

Armitage, J.A., Poston, L., Taylor, P.D., 2008. Developmental origins of obesity and the metabolic syndrome: the role of maternal obesity. Frontiers of Hormone Research 36, 73-84.

Barker, D.J.P., 1998. Mothers, Babies and Diseases in Later Life. Churchill Livingstone, London.

Bergstrom, T.C., 1997. A survey of theories of the family, Chapter 2. In: Rosenzweig, M.R., Stark, O. (Eds.), Handbook of Population and Family Economics. North Holland, New York, pp. 21-79.

Case, A., Deaton, A., 2006. Health and wellbeing in Udaipur and South Africa. In: Wise, D. (Ed.), Forthcoming in Developments in the Economics of Aging. University of Chicago Press for the NBER.

Costa-Font, J., Gil, J., 2008. Generational effects and gender height dimorphism in contemporary Spain. Economics and Human Biology 6 (1), 1-18.

Cupples, W.A., 2005. Physiological regulation of food intake. American Journal of Physiology-Regulatory, Integrative and Comparative Physiology 288, 1438-1443.

Food and Agriculture Organization of the United Nations, 2006. The developing world's new burden: obesity. Accessed on line July 27 , 2006 at http://www.fao.org/FOCUS/E/obesity/obes1.htm.

Furnham, A., Baguma, P., 1994. Cross-cultural differences in the evaluation of male and female body shapes. International Journal of Eating Disorders 15 (1), 81-89.

Holdsworth, M., Gartner, A., Landais, E., Maire, B., Delpeuch, F., 2004. Perceptions of healthy and desirable body size in urban Senegalese women. International Journal of Obesity 28, 1561-1568.

Kahn, K., Tollman, S.M., Garenne, M., Gear, J.S.S., 1999. Who dies from what? Determining cause of death in South Africa's rural northeast. Tropical Medicine and International Health 4 (6), 433-441.

Khan, M., 2006. The dual burden of overweight and underweight in developing countries. Population Reference Bureau. Accessed on line November 29, 2007 at http://www.prb.org/Articles/2006/TheDualBurdenofOverweightandUnderweightinDevelopingCountries.aspx.

Knight, B.S., Pennell, C.E., Adamson, S.L., Lye, S.J., 2007. The impact of murine strain and sex on postnatal development after maternal dietary restriction during pregnancy. Journal of Physiology 581 (Pt 2), 421-422.

Kohout, F., Berkman, L.A., Evans, D.A., Cornoni-Huntley, J., 1993. Two shorter forms of the CES-D depression symptoms index. Journal of Aging and Health 5 (2), 197-293.

Komlos, J., Breitfelder, A., Sunder, M., 2009. The transition to post-industrial BMI values among US children. American Journal of Human Biology 2, 151-160.

Leibbrandt, M., Poswell, L., Naidoo, P., Welch, M., Woolard, I., 2005. Measuring recent changes in South African inequality and poverty using 1996 and 2001 Census data. Working Paper 9629, Development Policy Research Unit, University of Cape Town.

Lingas, R.I., Matthews, S.G., 2001. A short period of maternal nutrient restriction in late gestation modifies pituitary-adrenal function in adult guinea pig offspring. Neuroendocrinology 73, 302-311.

Luo, Z., Mu S R., Zhang, X., 2006. Famine and overweight in China. Review of Agricultural Economics 28 (3), 296-304.

Martorell, R., Khan, L.K., Hughes, M.L., Grummer-Strawn, L.M., 2000. Obesity in women from developing countries. European Journal of Clinical Nutrition 54 (3), 247-252.

Mcmillen, C., Robinson, J.S., 2005. Developmental origins of the metabolic syndrome: prediction, plasticity and programming. Physiological Reviews 85, 571-633.

McMillen, I.C., Muhlhauster, B.S., Duffield, J.A., Yuen, B.S., 2004. Prenatal programming of postnatal obesity: fetal nutrition and the regulation of leptin synthesis and secretion before birth. Proceedings of the Nutrition Society 63 (3), 405-412.

Oken, E., 2009. Maternal and child obesity: the causal link. Obstetrics and Gynecology Clinics of North America 36 (2), 361-377.

Onyike, C.U., Crum, R.M., Lee, H.B., Lyketsos, C.G., Eaton, W.W., 2003. Is obesity associated with major depression? Results from the Third National Health and Nutrition Examination Survey. American Journal of Epidemiology 158 (12), 1139-1147. 
Osmani, S., Sen, A., 2003. The hidden penalties of gender inequality: fetal origins of ill-health. Economics and Human Biology 1 (1), 105-121.

Popkin, B.M., 1994. The nutrition transition in low income countries: an emerging crisis. Nutrition Reviews 52 (9), 285-298.

Popkin, B.M., Doak, C.M., 1998. The obesity epidemic is a worldwide phenomenon. Nutrition Reviews 56, 106-114.

Prentice, A.M., 2006. The emerging epidemic of obesity in developing countries. International Journal of Epidemiology 35, 93-99.

Puoane, T., Steyn, K., Bradshaw, D., Laubscher, R., Fourie, J., Lambert, V., Mbananga, N., 2002. Obesity in South Africa: The South African Demographic and Health Survey. Obesity Research 10, 1038-1048.

Ravelli, A.C.J., van der Muelen, J.H.P., Osmond, C., Barker, D.J.P., Bleker, O.P., 1999. Obesity at the age of $50 \mathrm{y}$ in men and women exposed to famine prenatally. American Journal of Clinical Nutrition 70, 811-816.

Ross, M.G., Beall, M.H., 2008. Adult sequelae of interuterine growth restriction. Seminars in Perinatology 32 (3), 213-218.

Stein, A.D., Kahn, H.S., Rundle, A., Zybert, P.A., van der Pal-de Bruin, K., Lumey, L.H., 2007. Anthropometric measures in middle age after exposure to famine during gestation: evidence from the Dutch famine. American Journal of Clinical Nutrition 85, 869-876.
Ulijaszek, S.J., 2003. Trends in body size, diet and food availability in the Cook Islands in the second half of the 20th century. Economics and Human Biology 1 (1), 123-137.

Varma, A., He, J., Weissfeld, L., Devaskar, S.U., 2003. Postnatal intracerebroventricular exposure to neuropeptide Y causes weight loss in female adult rats. American Journal of Physiology-Regulatory Integrative and Comparative Physiology 284, 1560-1566.

Wagner, K.-K, Scholz, H., 2003. The long-lasting impact of postnatal neuropeptide Y. American Journal of Physiology-Regulatory Integrative and Comparative Physiology 284, R1382-R1383.

Whitaker, R.C., Dietz, W.H., 1998. Role of the prenatal environment in the development of obesity. Journal of Pediatrics 132 (5), 768-776.

World Health Organization, 2000. Obesity: preventing and managing the global epidemic. Report of a WHO consultation. Technical Report Series 894, 1-253.

Zagorsky, J.L., 2005. Health and wealth. The late-20th century obesity epidemic in the U.S. Economics and Human Biology 3 (2), 296-313.

Ziebland, S.J., Robertson, J.J., Neil, A., 2002. Body image and weight change in middle age: a qualitative study. International Journal of Obesity 26 , 1083-1091. 